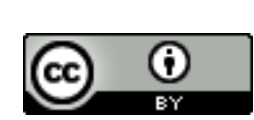

\title{
BACHELARD: \\ A APRENDIZAGEM CIENTÍFICA COMO RUPTURA
}

\begin{tabular}{c}
\hline BACHELARD: \\
SCIENTIFIC LEARNING AS RUPTURE \\
\hline BACHELARD: \\
EL APRENDIZAJE CIENTÍFICO COMO RUPTURA \\
\hline
\end{tabular}

\section{Marco Antonio Barroso ${ }^{i}$ Tarcísio Jorge Santos Pinto}

RESUMO: A presente pesquisa tem por objetivo relacionar a proposta epistemológica desenvolvida por Gaston Bachelard à sua ideia de progresso da ciência e de educação científica, fundamentando-se em uma leitura monográfica da obra do filósofo francês. Logo, o presente trabalho procura refletir sobre as contribuições da epistemologia bachelardiana à educação em geral e particularmente para o ensino de ciências em sua relação com a formação de professores. Em suas referências primárias o trabalho tem, como foco principal, a leitura do livro A formação do espírito científico, obra em que o pensador desenvolve sua visão crítica sobre o papel da educação científica para o desenvolvimento da ciência como um todo. Contudo, para uma melhor hermenêutica do texto, também serão utilizadas outras obras de Bachelard, como A filosofia do não e $O$ novo espírito científico, entre outros textos que tangenciam o assunto ora abordado.

PALAVRAS-CHAVE: Bachelard. Epistemologia. Educação científica.

ABSTRACT: The present research has the purpose of relating the epistemological proposal developed by Gaston Bachelard to his idea of science progress and scientific education, grounded on a monographic reading of the French philosopher's work. Therefore, the present work seeks to reflect on the contributions of bachelardian epistemology to education in general and particularly to the teaching of science in its relation with teacher education. In its primary references the research has, as main focus, the reading of the book The formation of the scientific mind, where the thinker develops his critic vision on the role of scientific education for the development of science as a whole. However, for a better hermeneutics of the text, other works of Bachelard will also be used, such as The philosophy of no and The new scientific spirit, among other texts that touch the approached subject.

KEYWORDS: Bachelard. Epistemology. Scientific education.

RESUMÉN: La presente investigación tiene por objetivo relacionar la propuesta epistemológica desarrollada por Gastón Bachelard a su idea de progreso de la ciencia y de la educación científica, fundamentándose en una lectura monográfica de la obra del filósofo francés. Por lo tanto, el presente trabajo busca reflexionar sobre las contribuciones de la epistemología bachelardiana a la educación en general y particularmente para la enseñanza de las ciencias en su relación con la formación de profesores. En sus referencias primarias el trabajo tiene como

Submetido em: 06/07/2017 - Aceito em: 15/09/2017 - Publicado em: 24/09/2017.

\begin{tabular}{|l|l|l|l|l|l|l|}
\hline (C) Rev. Educ. Perspec. & Viçosa, $M G$ & v.8 & n.2 & p.232-249 & maio/ago. 2017 & eISSN 2178-8359 \\
\hline
\end{tabular}


foco principal la lectura del libro La formación del espíritu científico, obra en la que el pensador desarrolla su visión crítica sobre el papel de la educación científica para el desarrollo de la ciencia en su totalidad. Sin embargo, para una mejor hermenéutica del texto, también se utilizarán otras obras de Bachelard, como $L a$ filosofía del no y El nuevo espíritu científico, entre otros textos que toquen el tema abordado.

PALABRAS CLAVE: Bachelard. Epistemología. Educación científica.

\section{INTRODUÇÃO}

Gaston Bachelard foi, em seu tempo, um homem plural. Químico por formação, educador por profissão, filósofo por opção. Nascido em 1884, em Bar-sur-Aube, cedo teve que trabalhar, devido à origem simples de sua família; seu objetivo era então tornar-se engenheiro telegráfico. Como primeiro passo para a vida profissional, termina a licenciatura em Matemática no ano de 1913. Contudo, com a eclosão da Primeira Guerra Mundial, em 1914, o futuro filósofo não pôde atingir o escopo de tornar-se engenheiro. Com o fim do serviço militar, em 1919, começa a lecionar física e química no colégio de sua cidade, ofício que continuará até 1930. Em 1920, licencia-se em Filosofia e, em 1922, consegue a "agregação de Filosofia", que o permite lecionar a matéria. Em maio de 1927, aos 43 anos, defende suas duas teses de doutorado, Docteur ès lettres, na Sorbonne, Essai sur la connaissance approchée, tese principal, e Étude sur l'évolution d'un problème de physique. La propagation thermique dans les solides. Já em suas teses é possível ver aquelas que serão suas principais contribuições metodológicas para o campo da filosofia da ciência: a ideia de ciência como construto da realidade e a epistemologia histórica. Em 1930, assume a cadeira de Filosofia das Ciências na faculdade de Dijon, posto em que ficará até 1940, quando assume a cadeira de História e Filosofia das Ciências, substituindo seu mestre Abel Rey, na Sorbonne.

Em uma rápida observação da trajetória de Bachelard, podemos identificar que sua vida espelha a dicotomia racional/onírico que está presente em suas obras. A ruptura epistemológica, o tempo que é, em sua verdade ontológica, um simples instante, um ponto no presente, se reflete no homem dual; em uma de suas faces, encontramos o cientista, ou o epistemólogo, imagem do dia, o ascetismo da razão; mas por outro lado, encontramos também o homem noturno, o ente onírico das imagens, o filósofo das artes. Essa dualidade é apresentada ao mundo em 1938, com a publicação das obras La Formation de l'esprit scientifique e La Psychanalyse du feu, em que encontramos a influência junguiana, animus e anima. Embora dual, a antropologia bachelardiana não é exclusiva, apolíneo e dionisíaco se complementam na formação do espírito científico e na criação artística. Uma vez que a 
construção da ciência é a construção de um mundo artificial, ele demanda do cientista a imaginação criadora, assim como o poeta precisa da palavra para construir suas imagens.

Mas onde encontramos a educação na obra de Gaston Bachelard e qual o papel dela para o desenvolvimento científico? Esta é a pergunta que o presente texto pretende responder. Quanto à metodologia para alcançar o escopo do trabalho, procedemos da seguinte forma: em um primeiro momento, foi feita uma revisão bibliográfica da obra do pensador francês, em que procuramos destacar conceitos chaves da sua epistemologia, dentro de sua concepção de história da ciência; em um segundo momento, buscamos destacar como os conceitos apontados anteriormente se aplicam à educação científica, segundo o próprio autor. Quanto às referências primárias, a pesquisa teve como foco principal a leitura do livro A formação do espírito científico, obra em que o pensador desenvolve, ainda que de forma indireta, sua visão crítica sobre o papel da educação científica para a construção da ciência como um todo; contudo, para uma melhor hermenêutica do texto e compreensão dos conceitos formulados pelo autor, também foram utilizadas outras obras de Bachelard, sendo elas: A epistemologia, A filosofia do não, Ensaio sobre o conhecimento aproximado e $O$ novo espirito científico. Foram utilizadas, como referências secundárias, os trabalhos dos principais comentadores da obra bachelardiana, destacando-se George Canguilhem, Françoies Dagognet, Hilton Japiassu, Helyana Barbosa e Marly Bulcão; a escolha da bibliografia secundária se deu com base na aproximação que os comentadores escolhidos promovem entre os conceitos bachelardianos e a educação.

Compreende-se que a pesquisa aqui proposta pode apontar caminhos para uma possível epistemologia do ensino de ciências, baseada na obra de Gaston Bachelard. Espera-se também levantar pistas que relacionem o ensino de ciências ao desenvolvimento científicotecnológico. Visamos assim contribuir para pesquisas já desenvolvidas no Brasil por nomes como Hilton Japiassu, Helyana Barbosa e Marly Bulcão, sobre a importância de Gaston Bachelard para as mais diversas áreas do pensamento, entre elas o campo da Educação.

\section{PARA UMA EPISTEMOLOGIA HISTÓRICA DA CIÊNCIA EM GASTON BACHELARD}

O trabalho do autor francês fundamenta-se na crítica ao continuísmo, corrente filosófica que vê os fatos históricos do presente como efeitos de causas passadas. Segundo Bachelard, alongando a percepção de tempo, os continuístas pretendem tornar homogêneos fatos e ocorrências que, vistos de perto, seriam considerados heterogêneos ou dialéticos, sendo a dialética aqui entendida como ciência da contradição. Podemos entender a presente crítica

\begin{tabular}{|c|c|c|c|c|c|c|}
\hline (C) Rev. Educ. Perspec. & Viçosa, $M G$ & v.8 & n.2 & p.232-249 & maio/ago. 2017 & eISSN 2178-8359 \\
\hline
\end{tabular}


como endereçada, principalmente, aos filósofos positivistas, que entendem a história como uma sucessão de fatos contínuos, colocando a perspectiva temporal centrada num passado distante ou, igualmente, num futuro longínquo. Entendida dessa forma, toda ciência passada se constitui como uma espécie de fazer anedótico e primitivo que, pela força mesma da história, caminha tranquilamente para um estágio último e acabado de saber. A partir dessa perspectiva, ignoram-se os embates próprios à construção do conhecimento, os quais, para nosso autor, promovem o real avanço científico. Vejamos como o epistemólogo francês expõe sua visão sobre o continuísmo:

\begin{abstract}
Uma vez que se faz narrativa contínua dos acontecimentos, crê-se facilmente reviver os acontecimentos na continuidade do tempo e dá-se, insensivelmente, a toda história a unidade e a continuidade de um livro. (...) Os continuístas gostam de refletir sobre as origens [grifo nosso], detêm-se na zona de elementaridade das ciências. (...) E, como a ciência sai lentamente do corpo dos conhecimentos comuns, crê-se ter a certeza definitiva da continuidade entre o saber comum e o saber científico (BACHELARD, 1984, p. 193).
\end{abstract}

Os continuístas negam, portanto, a ruptura epistemológica, defendida por Bachelard, introduzida no texto sob o conceito de rebentação. Rebentar, ou éclater, é um ato de ruptura abrupta, de separação total. Para legitimar esse conceito o autor nos dá uma série de exemplos retirados da própria história da ciência contemporânea. Afirma Bachelard:

É necessário, aliás, perguntar aos próprios cientistas a consciência das descontinuidades da ciência contemporânea. Eles assinalam essa descontinuidade que abordamos com toda precisão desejável. No prefácio ao colóquio do CNRS ${ }^{\text {ii }}$ sobre La liaison chimique (...), Edmonde Bauer, recordando a memória fundamental de Heitler e London sobre a molécula de hidrogênio, publicada em 1927, escreve: 'Esta molécula marca uma autêntica descontinuidade na história da química. Depois dela os progressos foram rápidos' (BACHELARD, 1984, p. 195).

Outras duas maneiras de promover a ideia de continuidade histórica da ciência seriam, segundo Bachelard, a noção de influência e a ideia de senso comum. Sob a égide da primeira, o mérito do progresso científico é atribuído a uma massa de intelectuais anônimos (BACHELARD, 1984, p.195). A noção de influência remete, necessariamente, a um passado longínquo (tipicamente romântico), que cria uma espécie de guarda-chuva que abriga as mais diversas tendências e harmoniza o que é, por "essência", díspare. Já sob a noção de progresso entre o senso comum e o conhecimento científico, Bachelard identifica um crime pedagógico. Escreve o autor que, "nos métodos do ensino elementar, adiam-se de ânimo leve os tempos de iniciação viris, procura-se conservar a tradição da ciência elementar, da ciência fácil" (BACHELARD, 1984, p.196). Ou seja, para o autor haveria, nos anos iniciais do ensino, uma tentativa de criar uma ligação entre o conhecimento do senso comum, típico do dia a dia das crianças, com o conhecimento científico, ensinado na escola; contudo isso seria um obstáculo 
ao verdadeiro desenvolvimento do intelecto científico infantil, uma vez que a ciência revela uma ruptura com esse tipo de conhecimento. Por fim, identifica as falácias da linguagem, utilizadas como subterfúgio para reforçar a ideia de continuidade (BACHELARD, 1984, p.197). O engodo falacioso ocorre quando se utiliza um termo científico como se ele fosse um correspondente ao que ocorre na natureza e não como uma analogia, o exemplo dado por Bachelard é a da imagem da gota d'água, desenvolvida por Niels Bohr para sintetizar as leis do núcleo atômico. Assevera Bachelard que, "as palavras gota, temperatura, e evaporação devem naturalmente ser postas entre aspas. Para os físicos nucleares, estas palavras estão, de certo modo, tacitamente redefinidas. Representam conceitos que são totalmente diferentes dos conceitos da física clássica" (BACHELARD, 1984, p. 200). Conforme ressalta Alberto Oliva, o discurso científico é composto por uma teoria da linguagem completa, composta de três níveis, que são:

1. A sintaxe concerne às relações subsistentes entre os signos sem que se leve em consideração a que se referem, em que contexto e por quem são empregados. As regras de formação definem que combinações entre os signos são aceitáveis e as suas regras de transformação, que enunciado pode ser derivado de outro(s). Representa a forma do discurso.

2. A semântica diz respeito às relações entre linguagem e realidade, palavras e objetos, enunciados e estados de coisas. A regra semântica especifica sob que condições um signo é aplicável a um objeto ou situação. Seu problema central é a verdade. Representa o conteúdo do discurso.

3. A pragmática se refere aos aspectos bióticos da comunicação, aos fenômenos biológicos, psicológicos e sociais que acompanham a utilização dos signos. As relações dos signos com seus usuários: quem diz o que, como, quando e com que finalidade. A estrutura linguística é, nesse caso, encarada como um sistema de comportamento. Representa o contexto do discurso (OLIVA, 2010, p.12-13).

Para que seja bem construído, o discurso científico não pode descurar de nenhuma dos três níveis linguísticos destacados acima. Ainda segundo OLIVA (2010, p.13), "quando tem pretensões cognitivas, deve ser: 1) formalmente impecável (requisito sintático); 2) referir-se de maneira unívoca a estados da realidade (requisito semântico). Só assim pode se habilitar a 3) convencer (requisito pragmático) a comunidade de pesquisadores do valor explicativo das teses defendidas".

A história da ciência se constrói, para o epistemólogo francês, por síntese, mas não no sentido dos continuístas. Não há uma teleologia natural que leve uma descoberta a outra. Para nosso autor, na ciência não há o conceito de antepassados, cada nova descoberta ressignifica todos os conceitos que ela envolve. Cada nova descoberta refaz, por completo, o discurso científico

\begin{tabular}{|c|c|c|c|c|c|c|}
\hline (C Rev. Educ. Perspec. & Viçosa, $M G$ & v.8 & n.2 & p.232-249 & maio/ago. 2017 & eISSN 2178-8359 \\
\hline
\end{tabular}


e por isso é uma nova síntese. Utilizando-se da mecânica ondulatória para exemplificar seu pensamento, escreve:

\begin{abstract}
Apesar de seu caráter revolucionário, apesar de ruptura com a evolução histórica regular, uma doutrina como a da mecânica ondulatória é uma síntese histórica, porque a história tinha-se detido por duas vezes em sistemas de pensamento perfeitamente elaborado: os pensamentos newtonianos e os pensamentos fresnellianos tomam um novo rumo e tendem para uma nova estética dos pensamentos científicos (BACHELARD, 1984, p. 205).
\end{abstract}

Somente essa aspiração à estética das hipóteses poderia abrir um novo caminho para o pensamento. Ou seja, somente a capacidade de perceber e conceber novas formas hipotéticas de pensar é que permitem a ciência sair da estagnação do pensamento bem elaborado.

Sob a perspectiva bachelardiana, é papel da história da ciência "distinguir o erro e a verdade, o inerte e o ativo, o prejudicial e o fecundo. (...). No domínio da história da ciência, é necessário, além de compreender, saber analisar, saber julgar". A história da ciência "deve descrever [a história], julgando-a, valorizando-a, eliminando toda possibilidade de um retorno a noções erradas" (BACHELARD, 1984, p.205). Embora devamos reconhecer as limitações temporais do fazer científico, podemos depreender do escrito por Bachelard que nem tudo é ciência. A história da ciência não é a história da cultura, em que não se pode impor os valores de seu tempo aos povos do passado.

A demonstração do progresso é um "elemento pedagógico da construção da cultura científica". O progresso é, afirma o espistemólogo francês, "a própria dinâmica que a história das ciências deve descrever” (BACHELARD, 1984, p. 205). O progresso da ciência é o progresso da razão, ou dito de outra forma, "é a história das derrotas do irracionalismo". (BACHELARD, 1984, p. 208). E se a própria noção de progresso se impôs é porque, segundo o autor, essa evolução se tornou manifesta no campo das ciências a partir do século XV. Bachelard ressalta, ao se referir ao conceito de progresso, que "ao estudar o essencial do progresso do pensamento científico, não nos cabe decidir quanto aos valores morais da ciência" e que sua pesquisa é "adstrita exclusivamente ao campo da epistemologia, tendo a ver tão somente com o progresso do conhecimento". (BACHELARD, 1977, p. 123).

A história do pensamento científico é uma história da atualidade, pois como assevera Bachelard, "o historiador da ciência, para bem julgar o passado deve conhecer o presente, deve aprender o melhor possível da ciência cuja história se propõe a escrever”. (BACHELARD, 1984, p. 209). Ao comentar a proposta bachelardiana de história da ciência, Barbosa e Bulcão salientam que, 
A obrigação de iluminar a historicidade das ciências pela atualidade da história da ciência é um estudo efêmero, por demais efêmero. Partindo do princípio de que a ciência é dinâmica e inconstante e de que suas teorias e métodos se transformam ao longo de seu desenvolvimento e que, portanto, os valores de racionalidade também se modificam, chega-se à conclusão de que a história das ciências é uma disciplina sempre jovem que tem de ser refeita constantemente (BARBOSA; BULCÃO, 2004, p. 63).

Mas, a partir do exposto até aqui, ficam as seguintes perguntas: como um filósofo que nega a ideia de continuidade em fluxo temporal perene pode defender o conceito de progresso científico? Como pode ele afirmar que o papel da epistemologia e da história da ciência é demarcar a diferença entre a verdade e a falsidade científicas, tendo como parâmetro a ideia de progresso? Para responder a estas questões, temos que compreender a noção de perfil epistemológico, tal como definida por Bachelard.

\section{A noção de perfil epistemológico}

Apesar dos apontamentos da seção anterior, não podemos atribuir ao pensamento de Bachelard características que ele não possui; ao contrário do princípio epistemológico proposto por Thomas Kuhn, em que as rupturas entre sistemas de pensamento são tão acentuadas que dão origem a paradigmas irredutíveis uns aos outros, em Bachelard essa ruptura radical não é possível. A noção de perfil epistemológico garante a coexistência de características históricas interpretativas diversas em um mesmo conceito. Essa coexistência, ainda que possua um tom negativo em termos de valores, para o autor marca um atributo importante no desenvolvimento de sua teoria da ciência. Ao contrário do que acontece nas teorias que apregoam a ruptura total e que nos deixam em dúvida sobre a possibilidade de caracterizar conceitos diversos em um mesmo universo de pensamento ${ }^{\mathrm{iii}}$, com a noção de perfil epistemológico temos a garantia de que ao nos referirmos a um determinado conceito, ele traz consigo uma diversidade de camadas interpretativas validadas em variados sistemas. É também a noção de perfil epistemológico que possibilita a averiguação objetiva do progresso de um conceito científico. Vejamos como isso fica mais claro com uma ilustração proposta para o conceito de massa, sugerido pelo próprio Bachelard (1978), no texto $A$ filosofia do não: 


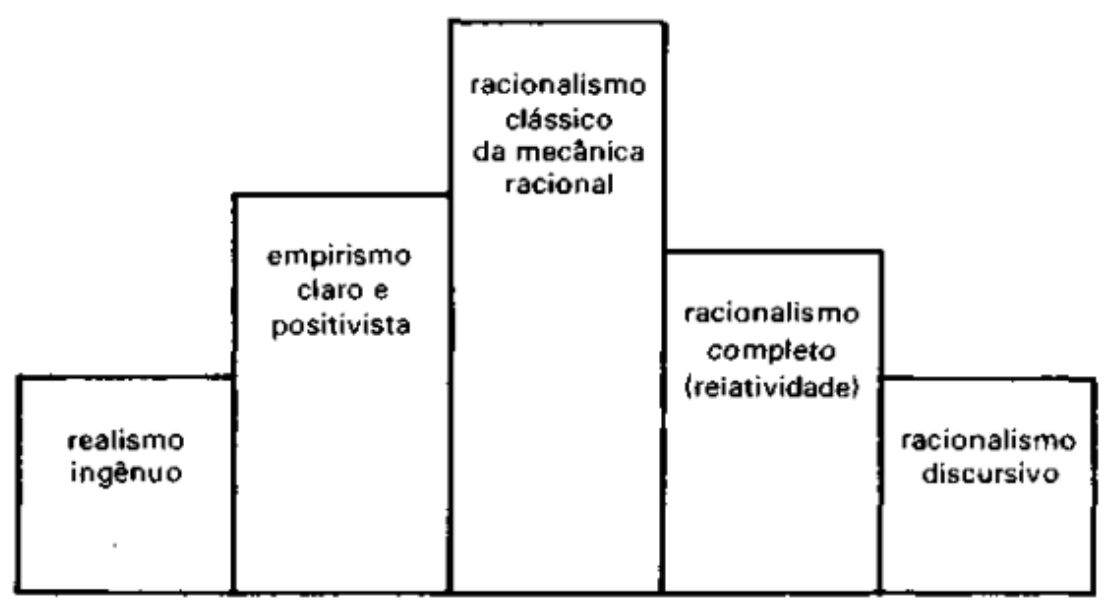

Figura 1. Gráfico proposto por Bachelard para demonstrar o perfil epistemológico do conceito de massa.

Fonte: BACHELARD, 1978, p. 25.

Como podemos ler na figura 1, o perfil epistemológico do conceito de massa concentra-se, destacadamente, no espectro $^{\text {iv }}$ do racionalismo clássico, ou seja, dentro da orientação epistemológica da física newtoniana. Todavia, vemos que outros espectros também permeiam este conceito, oferecendo-nos uma perspectiva de uma caminhada rumo a um progresso aparentemente linear. O racionalismo newtoniano ou kantiano seria a superação do empirismo claro e positivista e o próximo passo sugerido pela interpretação do gráfico seria, como consequência, racionalismo completo ou relativista. Entretanto, a "concentração histórica" de um conceito não necessariamente se apresenta em forma de gradual acúmulo e consequente superação de um perfil pelo outro, como se poderia imaginar, ou como sugeririam as epistemologias positivistas. Em um mesmo conceito, convivem simultaneamente os cinco espectros estabelecidos por Bachelard, sendo que a característica marcante, relativa a um conceito, não se encontra necessariamente vinculada aos avanços da ciência. Esta relação é fácil de observar quando comparamos o gráfico do conceito de massa ao do conceito de energia, desenvolvidos pelo autor. Vejamos: 


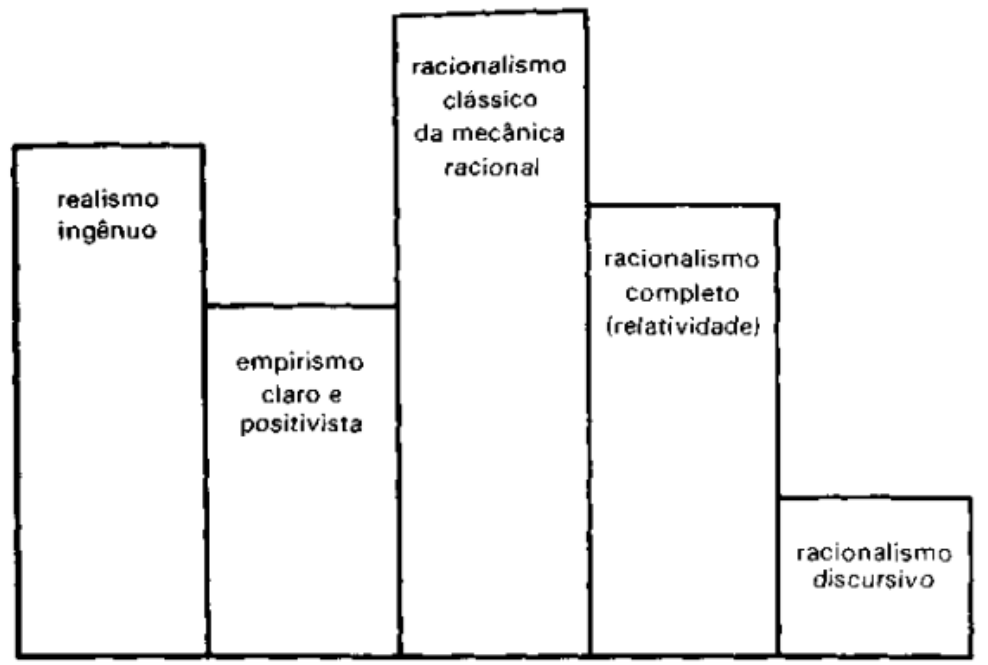

Figura 2. Gráfico proposto por Bachelard para demonstrar o perfil epistemológico do conceito de energia

Fonte: BACHELARD, 1978, p. 27.

A figura 2 coloca em evidência que, além do entendimento newtoniano, ainda vigora a compreensão do realismo ingênuo, ou senso comum, sobre o conceito de energia. Aplicando a ideia de perfil epistemológico como demarcação do conhecimento científico, destaca Bachelard que, no que tange

\begin{abstract}
às suas partes racionalistas, os dois perfis são semelhantes, tanto na formação newtoniana como na formação relativista. Com efeito, no que a nós se refere, quando nos orientamos para uma informação racionalista estamos tão seguros da nossa noção de energia como da nossa noção de massa. Por outras palavras, em relação aos nossos conhecimentos científicos, a nossa cultura é homogênea no que diz respeito aos dois conceitos de massa e de energia (BACHELARD, 1978, p. 27).
\end{abstract}

Todavia, no que diz respeito aos outros espectros que compõem o perfil epistemológico do conceito de energia, há uma tendência em nossa interpretação para atribuir-lhe características subjetivas, relativas aos conceitos psicológicos de vigor ou pujança. Ainda sobre a questão da formação histórica do pensamento científico, salienta Bachelard, "a reflexão filosófica que se exerce sobre o pensamento científico longamente trabalhado deve fazer que a nova ideia se integre num corpo de ideias já aceitas, mesmo quando esse corpo de ideais seja forçado, pelas novas ideias, a uma modificação profunda, como é o caso de todas as revoluções da ciência contemporânea". (BACHELARD, 1978, p. 341).

Para Barbosa e Bulcão, a proposta de história da ciência apresentada por Bachelard é original e ousada, servindo como reforço à ideia do racionalismo dialogado, proposto pelo autor (BARBOSA; BULCÃO, 2004). Segundo as comentadoras, essa nova noção de historicidade

\begin{tabular}{|c|c|c|c|c|c|c|}
\hline (C) Rev. Educ. Perspec. & Viçosa, $M G$ & v.8 & n.2 & p.232-249 & maio/ago. 2017 & eISSN 2178-8359 \\
\hline
\end{tabular}


traz em seu âmago "o verdadeiro sentido de racionalismo e de escola" pois o racionalismo, tal como formulado por Bachelard, "é o exercício vivo de pensar, um processo ininterrupto de reflexão e de diálogo que caracteriza a verdadeira escola" (BARBOSA; BULCÃO, 2004, p. 61-62). Dito de outro modo, a epistemologia histórica de Gaston Bachelard propõe, ainda que de for implícita, pois o autor não formula de forma sistemática uma filosofia da educação, que a escola seja um lugar de ruptura com o senso comum, em que a racionalidade possa ser constantemente inovadora e criativa.

\title{
BACHELARD E A EDUCAÇÃOO
}

Dagognet (1986, p. 26) destaca a crítica de Bachelard à educação científica tradicional e do "abuso do saber" como forma de violência: "Até a mais modesta sabedoria se põe atenta contra as certezas rígidas: ela denuncia o autoritarismo do mestre", pois o "mestre bachelardiano evita este grave escolho do sadismo" e "por definição, ensina menos do que acorda ou estimula". E, citando Bachelard, destaca:

\begin{abstract}
Os pais abusam, muitas vezes, mais ainda de seu saber do que seu poder... A omnisciência dos pais, em breve seguida a todos os níveis da instrução pela onisciência dos professores, instala um dogmatismo que é a negação da cultura. Quando este dogmatismo é atacado pelas loucas esperanças da juventude, ele faz-se passar profético. Pretende apoiar-se numa 'experiência' de vida. Ora, as condições do progresso são atualmente de tal móveis que a 'experiência de vida' passada, se uma sabedoria a pudesse resumir, é, quase fatalmente, um obstáculo a ultrapassar se se quer dirigir a vida presente (BACHELARD apud DAGOGNET, 1986, p. 26).
\end{abstract}

Bachelard defende uma educação racionalista, mas não nos moldes do racionalismo tradicionais, pois um "racionalismo autêntico nem se conta nem se impõe: é preciso viver a sua emergência, e o professor deve comunicar uma dinâmica" (DAGOGNET, 1986, p.26). Conforme destaca Japiassu, o racionalismo bachelardiano é aberto, pois os conceitos oriundos nessa forma de demarcação do saber científico devem ser retificados e deformados. Os fundamentos dos saberes científicos devem sempre serem reassegurados (JAPIASSU, 1976, p. 72).

O filósofo francês critica o ensino dedutivo por si só. Bachelard é um internalista em termos epistemológicos, ou seja, ele acredita no progresso da ciência e na verdade desta forma de saber. Mas ele é o que podemos chamar de um internalista moderado. Qualquer forma de teoria dedutiva só é validada cientificamente se já traz em sua formulação as indicações de que ela possa ser colocada à prova, de forma empírica. $\mathrm{O}$ mundo possui uma verdade, mas esta não é a verdade científica, que é aproximação, invenção e criação. A verdade científica é

\begin{tabular}{|l|l|l|l|l|l|l|} 
(C) Rev. Educ. Perspec. & Viçosa, $M G$ & v.8 & n.2 & p.232-249 & maio/ago. 2017 & eISSN 2178-8359 \\
\hline
\end{tabular}


o "fenômeno ordenado" racionalmente (de forma dedutiva) e reproduzido em laboratório (testado empiricamente). Para confirmar nossa afirmação, destacamos o próprio autor, que escreve:

\begin{abstract}
Teremos ocasião de provar que o fenômeno ordenado é mais rico que o fenômeno natural. Basta-nos por agora ter afastado do espírito do leitor a ideia comum segundo a qual a realidade é uma quantidade inesgotável de irracionalidade. A ciência física contemporânea é uma construção racional: ela elimina a irracionalidade dos seus materiais de construção. $O$ fenômeno realizado deve ser protegido contra toda a perturbação irracional. $\mathrm{O}$ racionalismo que nós defendemos fará assim face à polêmica que se apoia no irracionalismo insondável do fenômeno para afirmar uma realidade. Para o racionalismo científico, a aplicação não é uma derrota, é um compromisso. Ele quer aplicar-se. Se se aplica mal, modifica-se. Não nega por isso os seus princípios, dialetiza-os (BACHELARD, 1978, p. 5).
\end{abstract}

A fissão nuclear, que na natureza demora milhões de anos para acontecer, e que só acontece sob condições muito determinadas, é reconstruída pela mão humana, de forma que ocorra em um instante. A evolução das espécies e o aprimoramento genético são outros exemplos do valor cultural da ciência. "As trajetórias que permitem separar os isótopos no espectroscópio de massa não existem na natureza: é preciso produzi-las tecnicamente", afirma BACHELARD (1977, p. 123).

Vemos, também, o epistemólogo francês retomando o valor da publicidade das ideias, tal como estabelecido por Kant, e concordando com Popper, que nos ensina que a edificação da ciência moderna é uma elaboração feita pela e através da crítica e da negatividade. Destaca nosso autor que

[O] racionalismo dialético não pode ser automático [dedutivo] e não pode ser de inspiração lógica: é preciso que seja cultural, quer dizer que não é no segredo do escritório, na meditação de possibilidades mais ou menos evanescentes de um espírito pessoal, que ele se elabora... Não se pode, por mais que se pense, fazer uma axiomática em si completamente só... Uma construção solitária não é uma construção científica (BACHELARD, apud DAGOGNET, 1986, p. 27).

Bachelard reconhece o valor da cultura no desenvolvimento da ciência, assim como seu contemporâneo, Alexandre Koyré, que afirma:

O conhecimento científico, longe de repelir concepções oriundas de sistemas filosóficos ou teológicos, não raro os absorve e, mais do que isto, obtém da absorção seu próprio vigor. Sendo este o caso, trata-se de investigar o modo como a absorção de concepções de natureza filosófica, teológica, ou em termos mais gerais, metafísicas, favorece, ou mesmo viabiliza, o empreendimento científico (KOYRÉ apud FREITAS, 2010, p. 11). 
Bachelard, como Popper, acredita que há uma inter-relação entre o pensar e o fazer científicos. Por isso a valorização da experiência. Sobre esta valorização escreve BACHELARD (1978, p.5): “A realização de um programa racional de experiência determina uma realidade experimental sem irracionalidade". Conforme explica MALUF (2006, p. 37), Bachelard:

\begin{abstract}
Afirma que a atividade científica é um ato que deve ser colocado entre dois vetores epistemológicos: o da racionalização e o da experimentação. O objeto científico para ele não é fruto de uma representação, pois não se chega a sua verdade pela atividade puramente contemplativa, ou seja, é necessário construir um objeto que esteja para além do objeto imediato. Dessa forma, o objeto científico "[...] é o percurso que vai da realidade explicada ao pensamento explicado".
\end{abstract}

Para explicar a simplicidade e a efetividade do racionalismo na construção do saber, Bachelard se utiliza de uma passagem de Goethe e escreve: "Quando a criança começa a compreender que um ponto invisível deve preceder o ponto visível, que o caminho mais curto de um ponto a outro é concebido como uma reta, antes mesmo que se trace a linha no papel, ela sente com isso grande orgulho e certa satisfação" (BACHELARD, 1977, p. 55). Esta satisfação é, no entender de nosso autor, o sinal de uma "mutação filosófica", que demonstra passagem do saber de estágio empírico para um estágio racional (BACHELARD, 1977, p. $55)$.

Conforme destaca Dagognet (1986), podemos depreender duas consequências pedagógicas da recusa que Bachelard faz em entender a ciência como um sistema fechado, que funcionaria pelos seus próprios recursos, circunscrita a um espaço definitivo e atemporal e que poderia ser ensinada pela simples reconstrução racionalizada (dedutiva).

A primeira consequência da visão da ciência como um constructo móvel é a de que o verdadeiro professor deve sempre se colocar na posição de aprendiz. "Manter-se como estudante deve ser o voto secreto de um professor. Pelo próprio fato da prodigiosa diferenciação do pensamento científico, pelo fato da especialização necessária, a cultura científica coloca, sem cessar, o verdadeiro cientista na posição de aluno" (BACHELARD, apud DAGOGNET, 1986, p. 28). Com esta afirmação, destacam BARBOSA e BULCÃO (2004, 2004, p. 57-59), Bachelard “pretende mostrar é que a 'consciência de saber' está diretamente relacionada com o ato de ensinar', já que a objetividade só pode se fundamentar numa intersubjetividade" que, segundo as próprias comentadoras, traz implícita uma nova pedagogia, que "mostra que o racionalismo atual é, fundamentalmente, um racionalismo docente e discente". Para Bachelard, só se pode aprender, realmente, pela transmissão da composição do saber. Afirma o autor que, "ao examinar o saber repassado em suas profundezas metafísicas logo [se] adquire [uma] curiosa impressão de 'repassar' uma espécie

\begin{tabular}{|c|c|c|c|c|c|c|}
\hline C Rev. Educ. Perspec. & Viçosa, $M G$ & v.8 & n.2 & p.232-249 & maio/ago. 2017 & eISSN 2178-8359 \\
\hline
\end{tabular}


de 'composição de seu próprio ser', ou, mais exatamente ainda, de 'compor seu próprio ser'”. É assim que “o ser se torna ser de conhecimento" (BACHELARD, 1977, p. 22).

A segunda consequência da visão bachelardiana é que também o aluno se torna um professor para seu mestre. Frisa nosso autor que "a dialética do mestre e do aluno inverte-se sempre. No laboratório, um jovem pesquisador pode adquirir conhecimento tão avançado de certa técnica ou tese que, na questão, torna-se mestre de seu mestre" (BACHELARD, 1977, p. 31).

Concernente ao pensamento de nosso autor, fazer ciência é viver plenamente no tempo presente, no próprio instante. Por outro lado, dado o imperativo da crítica, da publicidade das ideias e da aprendizagem negativa, pela valorização do erro, o saber adquirido só se confirmará pelo ensino. Frisa Bachelard que:

Quem é ensinado deve ensinar. Uma instrução que se recebe sem que se transmita forma espíritos sem dinamismo, sem autocrítica. Sobretudo nas disciplinas científicas, uma deste gênero fixa no dogmatismo um conhecimento que deveria ser um impulso para uma diligência inventiva. E, acima de tudo, falha em dar a experiência psicológica do erro humano (BACHELARD, apud DAGOGNET, 1986, p. 28).

Para Bachelard, como vimos anteriormente, a ciência se faz de modo descontínuo, por um processo de ruptura com o passado e a construção de uma nova realidade. Podemos deduzir, então, que para o autor, qualquer tipo de ensino científico que se fundamente na continuidade e no senso comum impede, forçosamente, o bom desenvolvimento da ciência, transformandose em um obstáculo epistemológico. Os obstáculos induzem à formulação de perguntas errôneas, que por sua vez impede a correção do objeto de estudo e traz a consequente manutenção do erro. Comenta Japiassu acerca da relação entre o fazer científico e de seu ensino que: "Tanto o trabalho científico de pesquisa quanto o de seu ensino exigem que os pesquisadores e os educadores criem dificuldades para si próprios. O importante é que saibam criar dificuldades reais e eliminar os obstáculos falsos ou as dificuldades simplesmente imaginárias” (JAPIASSU, 1976, p. 73). Frisa Maluf (2006, p. 38) que,

Partindo da convicção de que o real oculto é uma construção humana e mais rico que o dado imediato, Bachelard propõe a negação do objeto imediato, afirmando que a ciência moderna não é uma continuidade da ciência clássica e que o conhecimento científico não se dá em continuidade ao conhecimento comum.

E, um pouco mais à frente, acrescenta:

Bachelard afirma que para conhecer a evolução do espírito científico, deve-se visualizar o conhecimento como um tecido de erros positivos, o que implica a correção de erros subjetivos, de forma que o espírito científico somente pode ser

v.8 1 n.2

p.232-249

maio/ago. 2017

eISSN 2178-8359 
construído destruindo o espírito não científico. É negando as experiências anteriores que uma experiência vai se firmar como nova, demonstrando que o espírito científico deve dialetizar todas as formas de conhecimento, sem dar privilégio às explicações generalizantes. Trata-se de uma proposição de ruptura entre o conhecimento sensível e conhecimento científico, o que não seria exagero definir que a ciência instrumental é uma transcendência da ciência de observação natural. Essa forma de pensar cientificamente coloca-nos sempre em um campo epistemológico intermediário entre a teoria e a prática, de forma que o fenômeno ordenado sempre se apresentará mais rico que o fenômeno natural (MALUF, 2006, p. 39-40).

É preciso lembrar, aqui, em que lugar teórico o autor situa sua fala. Bachelard formula seu pensamento a partir das novas descobertas da física moderna, destacando-se principalmente as descobertas da física quântica. Conforme acentuam Barbosa e Bulcão,

Foi grande a influência da teoria da relatividade de Einstein sobre o pensamento de Bachelard. As novas revoluções científicas do começo do século XX, importantes para a física e a química, tornaram muito estreita a ligação entre a matemática e a experiência e abalaram as filosofias científicas vigentes, como o positivismo, o realismo ou mesmo o convencionalismo (BARBOSA; BULCÃO, 2004, p. 35).

Geometria não-euclidiana, lógica não-aristotélica, indeterminismo, são palavras chaves para compreender o pensamento epistemológico de Bachelard, e por consequência sua visão sobre o ensino das ciências em geral. Afirma o autor, ao comentar o alcance epistemológico do princípio de incerteza $^{\mathrm{v}}$, que, "a racionalização opera pelas vias mais diversas e mais indiretas" (BACHELARD, 1974, p. 220).

Retomando o tema kantiano da razão ordenadora, Bachelard afirma que fazer ciência é dar coerência atemporal aos instantes que, na natureza, se encontram isolados e desarticulados. É o pensamento criador da ciência "que dá mais continuidade à vida. [...]. E fazendo uma crítica ao pensamento bergsoniano, enfatiza: "No seu simples aspecto biológico, a vida não 'associa' fortemente o tempo", sendo, pois, essa associação uma construção da racionalidade humana. Todavia, alerta: "o pensamento racional demasiado linear pode, no entanto, levar à obstinação. Pode conduzir a evolução a um impasse”. (BACHELARD, 1974, p. 220). E seria papel da educação preparar as crianças para se tornarem imunes a essa razão ditatorial. É papel do educador, permitir que os educandos cresçam com um psiquismo aberto. Dessa proposta de educação deveria surgir um novo sujeito, como frisam Barbosa e Bulcão, não mais um

Sujeito puro e distinto, imediatamente dado a si mesmo numa certeza de si que seria não só garantia da verdade, como também se imporia como alguém que domina seu saber. Para Bachelard não há sujeito originalmente construído, nem sujeito originalmente constituinte. A função do sujeito é a de se enganar, de se retificar e, 
portanto, de ir se formando ao longo de um esforço inerente ao processo de conhecimento (BARBOSA; BULCÃO, 2004, p. 55).

A educação passa a ser assim um trabalho ativo em que o conhecimento é construído em uma via de mão dupla, entre sujeito e objeto. Cabe ao educador ajudar ao educando, mediante a construção do conhecimento científico, aprender a eliminar as primeiras impressões irrefletidas, oriundas do primeiro contato com seu objeto de estudo. Essas primeiras impressões espontâneas são obstáculos que impedem a construção objetiva do conhecimento - finalidade do saber científico. Conhecer implica, pois, no "refazer-se constante e ininterrupto do sujeito que se retifica, afastando obstáculos e ilusões primeiras para alcançar em seguida a objetividade" (BARBOSA; BULCÃO, 2004, p.55). Destaca ainda Fabre que "o pensamento bachelardiano é o esforço para reintegrar o trabalho ao lazer e resgatar, assim, a noção grega de 'scholé, na ideia de formação permanente" (FABRE apud BARBOSA; BULCÃO, 2004, p. 56). De acordo com o que afirma o pensador francês, "precisamente uma das funções do ensino científico é suscitar dialéticas. [...]. Coloca-se um assunto em oposição a outro. Essa oposição pode ser inteiramente racional. Ela perturba a racionalidade do discípulo em benefício de uma racionalidade de mais ampla aplicação do mestre" (BACHELARD, 1977, p. 29).

\section{CONCLUSÃO}

Nosso trabalho procurou apontar algumas das contribuições do pensamento epistemológico de Gaston Bachelard para a pesquisa em ensino de ciências; pela conceituação de história da ciência, desenvolveu a noção de ruptura epistemológica, apontando a oposição ao pensamento continuísta da filosofia positivista. Mostramos, também, que o progresso da ciência ocorre por rupturas com o senso comum e que a experiência científica deve, necessariamente, contradizer a experiência orientada pelo senso comum.

Procuramos demonstrar que, assim como ocorre na história da ciência, tal como interpreta Bachelard, também a construção da educação em geral e, em especial o saber científico principalmente em suas bases escolares - deve sempre partir da ruptura com as impressões ingênuas do senso comum, superando os obstáculos que são impostos pela própria estagnação do conhecimento.

Tomando a epistemologia bachelardina como referencial teórico para a possível construção de uma filosofia da educação, fica impossibilitada a visão de uma educação espontaneísta e com base na intuição. Contudo, por outro lado, é preciso entender que as ciências

\begin{tabular}{|c|c|c|c|c|c|c|}
\hline (C Rev. Educ. Perspec. & Viçosa, $M G$ & v.8 & n.2 & p.232-249 & maio/ago. 2017 & eISSN 2178-8359 \\
\hline
\end{tabular}


contemporâneas estabeleceram limites e aplicações para a racionalidade. Ainda no que se refere a uma "filosofia geral da educação" em Bachelard, depreende-se que a racionalidade aplicada, ou regionalizada, tenha como consequência o estímulo à pluralidade dos métodos pois não há "o método científico", mas métodos que procuram responder a problemas.

No que tange ao ensino de ciências em sua relação com a formação de professores, defendemos que, para que tenhamos uma ciência viva, temos que igualmente ter uma educação científica fundamentada em uma epistemologia que entenda o fazer científico como algo dinâmico, reconstruído diuturnamente com base na crítica racional. A educação deve ser dialética, no sentido que Bachelard dá a este conceito, ou seja; a educação deve ser feita pela apresentação de ideias e pelo estímulo a critica das ideias apresentadas. Como assevera MALUF (2006, p.159), "fazer e ensinar ciências em Bachelard não é reproduzir os experimentos protocolares que servem para referendar uma determinada teoria quando trabalhados a posteriori".

Por fim, conforme acentuam Barbosa e Bulcão, "A educação e a formação implicam primordialmente na desconstrução e reforma do sujeito que se refaz, refazendo suas próprias ideias, retificando conceitos aprendidos anteriormente, fazendo, assim, de seu dinamismo e de sua inconstância o requisito pedagógico mais importante e mais fundamental" (BARBOSA; BULCÃO, 2004, p.57). Nesse sentido, para Bachelard, todo professor deve pensar em sua formação como contínua, na medida em que entenda o conhecimento como algo provisório e sempre reconstruído. É preciso aprender a identificar os obstáculos que se impõem a construção do conhecimento, sendo que, um dos principais obstáculos a ser superado é o da certeza do saber. O ato de ensinar deve ser ao mesmo tempo, um ato de aprender, de renovação do espírito científico e da formação de uma racionalidade aberta.

\section{REFERÊNCIAS}

BACHELARD, Gaston. A epistemologia. Lisboa: Edições 70, 1990a.

\section{BACHELARD, Gaston. A filosofia do não; O novo espírito científico; A poética do espaço. São Paulo: Abril Cultural, 1978.}

BACHELARD, Gaston. A filosofia do não: O novo espírito científico; A poética do espaço. São Paulo: Abril Cultural, 1984. 
BACHELARD, Gaston. A formação do espírito científico. Rio de Janeiro: Contraponto, 1996.

BACHELARD, Gaston. Ensaio sobre o conhecimento aproximado. Rio de Janeiro: Contraponto, 2004.

BACHELARD, Gaston. Estudos. Rio de Janeiro: Contraponto, 2008.

BACHELARD, Gaston. O materialismo racional. Lisboa: Edições 70, $1990 \mathrm{~b}$.

BACHELARD, Gaston. O pluralismo coerente da química moderna. Rio de Janeiro: Contraponto, 2009.

BACHELARD, Gaston. O racionalismo aplicado. Rio de Janeiro: Zahar ed., 1977.

BADARÓ, Cláudio Eduardo. Epistemologia e ciência: reflexão e prática em sala de aula. Bauru, SP: EDUSC, 2005.

BARBOSA, Elyana; BULCÃO, Marly. Bachelard: pedagogia da razão, pedagogia da imaginação. Petrópolis, RJ: Vozes, 2004.

BULCÃO, Marly. O racionalismo da ciência Contemporânea: uma análise da Epistemologia de Gaston Bachelard. Rio de Janeiro: Ed. Antares, 1981.

CANGUILHEM, Georges. Introducción a Bachelard. Buenos Aires: Ediciones Caldén, 1973.

CESAR, Constança Marcondes. Bachelard: ciência e poesia. São Paulo: Paulinas, 1989. DAGOGNET, François. Bachelard. Lisboa: edições 70, 1986.

FREITAS, Renan Springer. Judaísmo, racionalismo e teologia cristã da superação: um diálogo com Max Weber. Belo Horizonte: Argvmentvm, 2010.

JAPIASSU, Hilton. Para ler Bachelard. Rio de Janeiro: Francisco Alves, 1976.

KOYRÉ, Alexandre. Estudos de história do pensamento científico. Rio de Janeiro: Forense Universitária, 1991.

KUHN, Thomas Samuel. A estrutura das revoluções científicas. São Paulo: Perspectiva, 1994.

\begin{tabular}{|l|l|l|l|l|l|l|}
\hline (C) Rev. Educ. Perspec. & Viçosa, $M G$ & v.8 & n.2 & p.232-249 & maio/ago. 2017 & eISSN 2178-8359 \\
\hline
\end{tabular}


MALUF, Vitérico Jabur. A contribuição da epistemologia de Gaston Bachelard para o ensino de ciências. 2006. (Tese de doutorado) - Universidade Estadual Paulista "Júlio de Mesquita Filho", Araraquara, 2006.

MIALARET, Gaston. Le nouvel esprit scientifique et les sciences de l'éducation. Paris: Puf, 2015.

OLIVA, Alberto. Filosofia da ciência. Rio de Janeiro: Zahar, 2010.

QUILET, Pierre (Org.). Introdução ao pensamento de Bachelard. Rio de Janeiro: Zahar Editores, 1977.

PAIVA, Rita. Uma inserção no universo Bachelardiano: o alargamento da imaginação e a obsolescência do objetivismo na ciência e na sociologia. 1997. (Dissertação Mestrado) Universidade de São Paulo, São Paulo, 1997.

\section{NOTAS}

\footnotetext{
ii Centre National de la Recherche Scientifique.

iii Poderíamos chamar, por exemplo, ao mesmo tempo, de física a teoria sobre o movimento dos corpos em Aristóteles e Newton?

iv Bachelard estabelece cinco (5) espectros históricos para a formação de um perfil epistemológico; são eles: realismo ingênuo - empirismo claro e positivista — racionalismo newtoniano ou kantiano — racionalismo completo ou relativista — racionalismo dialético (BACHELARD, 1978, p. 25).

v De forma resumida, Princípio da incerteza é o termo utilizado para designar o estado de um elétron, este princípio foi criado por Werner Heisenberg (1901-1976) em 1927 e transformou-se num enunciado da mecânica quântica. O princípio afirma que não se pode determinar simultaneamente o valor exato de um componente do momento px de uma partícula e também o valor exato da coordenada correspondente, x. Ou seja, quando se determina a posição de um elétron na eletrosfera do átomo não se pode determinar sua posição e, consequentemente, quando se determina sua posição, não se pode determinar sua velocidade.
}

\section{Sobre os Autores}

'Marco Antonio Barros - Mestrado e Doutorado em Ciência da Religião Universidade Federal de Juiz de Fora. Professor e pesquisador da Universidade do Estado de Minas Gerais (Unidade de Ubá). E-mail: marco.barroso78@gmail.com

ii Tarcísio Jorge Santos Pinto - Professor Adjunto III da Universidade Federal de Juiz de Fora. Email: tarcisio.pinto@ufjf.edu.br 